\title{
Silicone rubber encapsulation for an endoscopically implantable gastrostimulator
}

Laurent Lonys ${ }^{*}$, Anne Vanhoestenberghe ${ }^{\#}$, Nicolas Julémont ${ }^{*}$, Stéphane Godet ${ }^{\dagger}$, Marie-Paule Delplancke ${ }^{\dagger}$, Pierre Mathys ${ }^{*}$, Antoine Nonclercq ${ }^{*}$

*Biomedical Stimulation and Monitoring research group (BISTIMO), Université Libre de Bruxelles, Avenue F.D. Roosevelt 50 CP165/51, 1050 Bruxelles

"Implanted Devices Group, Medical Physics \& Bioengineering Dept, UCL, Gower Street WCIE 6BT London

${ }^{\dagger}$ Materials engineering, characterization, synthesis and recycling (4MAT), Université Libre de Bruxelles, Avenue F.D. Roosevelt 50 165/63, 1050 Bruxelles

Corresponding Author:

Laurent Lonys,

e-mail: 1lonys@ulb.ac.be

tel: +3226502829

fax: +3226502482

The total number of words of the manuscript, including entire text from title page to figure legends: $\mathbf{5 2 6 9}$

The number of words of the abstract: $\mathbf{1 8 3}$

The number of figures: $\mathbf{8}$

The number of tables: $\mathbf{3}$ 


\section{Abstract}

Gastrointestinal stimulator implants have recently shown positive results in treating obesity. However, the implantation currently requires an invasive surgical procedure. Endoscopy could be used to place the gastric stimulator in the stomach, hence avoiding the riskier surgery. The implant then needs to go through the oesophagus and be located inside the stomach, which imposes new design constraints, such as miniaturization and protecting the electronic circuit against the highly acidic environment of the stomach. We propose to protect the implant by encapsulation with silicone rubber. This paper lists the advantages of this method compared to the more usual approach of a hermetic enclosure, then presents a method to evaluate the underwater adhesive stability of six adhesive/substrate couples; using repeated lap-shear tests and an elevated temperature to accelerate the aging process. The results for different adhesive/substrate couples tested, presented on probability plots, show that FR4 and alumina substrates with MED4-4220 silicone rubber are suitable for a first implantable prototype. We then compare these with the predicted lifetimes of bonds between historical standard silicone rubber DC3140 and different substrates, and describe the encapsulation of our gastrostimulator.

\section{Keywords}

Gastric electrical stimulation; endoscopic implantation; obesity; encapsulation; packaging; lap-shear test; silicone rubber; accelerated testing. 


\section{Introduction}

Obesity has reached epidemic proportions throughout the world, with more than 500 million adults affected [15]. It is commonly associated with various health issues such as cardiovascular diseases, diabetes and musculoskeletal disorders [38]. Obesity also has important economical consequences both for the obese patients and for society [38].

Bariatric surgery, mainly recommended to patients with a body mass index (BMI) ranging between 30 and 50, is one of the most common techniques used to induce weight loss [21]. Although effective, it suffers from important drawbacks such as its considerable costs and invasiveness, as well as long term weight regain [20]. Gastric electrostimulation, a recent technique aiming to induce satiety by applying current pulses to the stomach, has shown promising results in terms of effectiveness [19]. However, as laparoscopy is used to implant the gastrostimulator, those improvements are somewhat limited as the method is still invasive. In this regard, placing the gastrostimulator using endoscopic techniques is highly attractive because it would be reversible, less invasive and less expensive [21]. Being more affordable and less risky, the technique could be offered to a greater number of obese persons.

\section{Challenges of endoscopically implantable stimulator}

Endoscopically implanted gastrostimulators are however very challenging to design [25]. First, due to the passage through the oesophagus, we estimate, based on previous experimental studies and existing endoscopic devices [21], that the device cannot exceed a maximum volume of $5 \mathrm{~cm}^{3}$ and a diameter of $18 \mathrm{~mm}$. The large housings commonly used for implantable electronic devices (such as the pacemaker) are therefore unsuitable. Second, the device needs to have adequate anchoring in the stomach to avoid migration or detachment and withstand stomach contractions. Third, the device needs to be easily secured using endoscopic tools. Fourth, the power supply should neither be cumbersome nor require too regular endoscopies to replace the implant. Fifth, the device packaging must resist the acidic stomach environment, as described hereunder. 


\section{Implant packaging}

The implant packaging is of major importance as it protects the implant from the humid and acidic stomach environment (the $\mathrm{pH}$ in the stomach can be as low as 1 [3]). Packaging prevents corrosion and provide some mechanical protection to the components of the electronic circuit, therefore preventing functional failure or erratic behaviour of the implant that could present a risk to the patient. The material used for the packaging should obviously be biocompatible.

The most popular packaging method consists in using hermetically sealed housings, generally made of metal, ceramic or glass with hermetic feedthroughs. The well-known pacemaker has proven that such protections do last for decades. However, hermetic hard shells present various drawbacks:

- They tend to be heavy and bulky, yet, the most popular designs, which were initially conceived 50 or more years ago, have reached the limits of miniaturisation achievable. This is becoming increasingly relevant with the trends towards implant miniaturisation driven by the development of new applications, such as gastric implants and others (e.g. retinal and spinal stimulation).

- The manufacturing processes rely on expensive tooling, often build specifically to a part's dimensions, which is a considerable financial burden for the production of very small batches, typical of the early prototyping stages of a product development.

- They require feedthrough, since most implants are to interact in some way with the human body (recoding, simulation, etc.). Therefore, a further protection level is also needed for all conductive parts outside the protective shell. This is often achieved with silicone rubber encapsulation. Note that some designs use the substrate as a part of the hermetic enclosure [17], achieving this way higher feedthrough density, but still requiring silicone rubber encapsulation.

- Hermeticity tests, needed to assess the hard shell's and seal's hermeticity, are unreliable for implants with a small internal volume [22, 35]. Again, this is becoming increasingly problematic since recent implant designs require such small dimensions.

- Hermetic packages often use materials that affect RF communication. Although some attempts were made to design a transparent window for RF 
communication $[1,40,41]$, the procedure is very expensive and the resulting designs were large.

Therefore, this protection method is not suitable for many applications, including ours.

Another way of protecting the implant consists in encapsulating all the components with silicone rubber. This method is used in commercial applications and gives implant lifetimes of several decades [2]. It was briefly reviewed by Vanhoestenberghe et al. [36] and the two methods are illustrated in Fig. 1. The key to the success of this method is an appreciation that while silicone rubber is highly permeable to water vapour [33], its presence over a substrate can prevent the formation of liquid water, hence avoiding the formation of conductive paths between conductors, and corrosion. Therefore, it is crucial that the silicone rubber should strongly adhere to the substrate, and that the manufacturing method should prevent the creation of any voids that would lead to water condensation over electrical pads. If there is no loss of adhesion between the encapsulant and all the surfaces, there will be no corrosion inducing a potential failure. The implant life can thus be related to the life of the adhesive joint in situ. It is therefore critical to evaluate the long-term stability of the adhesive bond, between the encapsulant and the surfaces it covers, under operating conditions. Various silicone rubbers and substrates have already been tested in earlier experiments [9-11]. However, to the best of our knowledge, no studies have assessed their behaviour in the acidic environment of the stomach.

Further, silicone rubber has already been used to encapsulate a gastrostimulator. However, no information were presented justifying the choice of material, and the device was removed after two hours in vivo, so that no information regarding long-term adhesion, or general efficiency of the protection method, could be deduced [5].

In this article, we describe the method we use to evaluate the long-term stability of the adhesive bond between several couples of substrate and silicone rubber. Although not novel, it has never been described fully in a publication. It is based on a survival analysis, using a Weibull distribution, of lap-shear samples aged at an increased temperature to accelerate the failure rate. We also discuss, for the first time, how to interpret the results in a general context, and offer an illustration with materials specifically selected for our application. Two adhesive silicone 
rubbers are tested in vitro on typical implant substrates at worst-case stomach $\mathrm{pH}$. The best one is proposed for a gastric implant and compared with historical standards.

\section{Methods}

This section describes the material selection, sample preparation, accelerated aging, event recording and standardized lap-shear method, statistical analysis and interpretation.

\section{Material selection}

The selected silicone rubbers are Dow Corning DC3140 and Nusil MED4-4220 (see Table 1 for major properties). The selected substrates are glass, alumina and glass-reinforced epoxy (FR4).

DC3140 was chosen because of its good adhesion to alumina $[9,10]$ and its wide use in the literature. It has long been considered the most suitable of 1-part silicone rubbers, amongst other because its cure evolves an alcohol, while most 1part silicone rubbers evolve acetic acid that may contribute to the corrosion of underlying metal surfaces. It is, however, not indicated for medical use and its cure requires atmospheric moisture, making it unsuitable for moulding [6]. Biocompatible MED4-4220 was developed by Nusil for encapsulating and was chosen as a newer silicone rubber presenting interesting properties such as a high tensile modulus and a wide range of cure temperatures and times (see Table 1). While 2-part silicone rubbers are suitable for moulding, they are unfortunately more sensitive to contamination than 1-part rubbers. Indeed, the platinum catalyst used for 2-part adhesives is very sensitive to contamination [27]. This can impede the chemical reactions between the two parts of the silicone rubber and prevent a complete cure, the resulting product remaining tacky at best. The catalysts used in 1-part rubbers are less sensitive to poisoning.

The adherent materials FR4 and alumina were chosen because they are typically used as electronic circuit substrates. Glass was also considered because its performance, with DC3140 as an adherent, in previous experiments at pH 4 was remarkable, and because the bonds of various silicone rubbers, including DC3140, to both glass and alumina have already been showed to be satisfactory $[9,10]$. 


\section{Sample assembly and cleaning}

All substrates measure $25.4 \mathrm{~mm}$ by $25.4 \mathrm{~mm}$. Those dimensions were chosen to allow easy comparison with previous studies. The thickness was $1 \mathrm{~mm}$ for glass, $0.7 \mathrm{~mm}$ for alumina and $1.6 \mathrm{~mm}$ for FR4. The impact of the substrate thickness on the long-term stability of the adhesive bond is unlikely to be significant. The water vapour will permeate through the silicone rubber in a matter of minutes to hour [33] while the water vapour permeability of the three substrate materials tested is comparatively much higher.

The FR4 pieces were immersed in overactivated ferric chloride solution to remove the copper layer. This method is commonly used to remove copper from FR4 when etching printed circuit boards.

The substrates were cleaned with an alkaline cleaning solution containing $10 \mathrm{ml}$ of Teepol and $250 \mathrm{~g}$ of $\mathrm{Na}_{3} \mathrm{PO}_{4}$ diluted in deionized water to 21 . All parts were then rinsed in flowing deionized water until the conductivity of the rinse water, $120 \mathrm{nS} / \mathrm{cm}$ at the output of the deionizer, was lower than $300 \mathrm{nS} / \mathrm{cm}$ when measured at the output of the rinsing bath.

Each sample was built with two adherent pieces, bonded with silicone rubber. The adhesive layer had a $500 \mu \mathrm{m}$ thickness and a 25.4 by $3 \mathrm{~mm}$ area (Fig. 2). Three different joining jigs were built, to accommodate for the different substrate thicknesses while keeping the adhesive layer thickness constant at $500 \mu \mathrm{m}$ (Fig. 3). The adhesive layer was first applied with a gun on the lower substrate (on the right side of the Fig. 2), before carefully laying the second substrate above. The bonded samples were then cured at $60^{\circ} \mathrm{C}$ overnight.

\section{Accelerated aging}

All samples were immersed in a simulated gastric fluid (DMC030-06 Simulated Gastric Fluid from ProSense B.V., Netherlands) at $100^{\circ}$ C. It is the first time that such tests were performed in a simulated physiological fluid instead of distilled water.

Working at this elevated temperature, much higher than that of the body, accelerates the failure rate. It does not however, to the best of our knowledge, introduce new failure modes not present at the operating temperature. We are therefore only studying the adhesive failures that would occur in use. 
PEK Donaldson studied the underwater stability of the adhesive joints between 1 and 2-part silicone rubbers and several adherents. He showed that the failure rate follows an Arrhenius relationship with temperature [12]. An acceleration factor, A, comparing the failure rates at two temperatures $T$ and $T+\Delta T$, can then be calculated using the following equation:

$$
A=e^{\left[\frac{E a}{k} *\left(\frac{1}{T}-\frac{1}{T+\Delta T}\right)\right]}
$$

where $k$ is the Boltzmann constant and $\mathrm{E}_{\mathrm{a}}$ the activation energy of the joint failure. The activation energy depends on the adhesive/substrate couple tested, as well as, to a lesser extend, the relative humidity and temperature [36]. Based on PEK Donaldson's results for DC3140 on alumina at pH 7 between 70 and $100^{\circ} \mathrm{C}$, an activation energy of $0.7 \mathrm{eV}$ was used when calculating the acceleration factor (see section "Results").

\section{Timing of lap-shear tests and recording of failures}

Lap-shear tests, pulling with a $5 \mathrm{~kg}$ force, were performed periodically. The intervals between the tests were defined as one tenth of the time from the beginning of the experiment or daily, whichever was the longer, meaning for example that until the 20th day, the samples were tested daily. It is worth noting that to keep a manageable number of samples, they were not removed after each "pull" but re-immersed in the gastric liquid, potentially accelerating further their failure rate. Consequently, the calculated survival rate is underestimated compared to an ideal case with removal of every sample tested.

A test can have either of the three outcomes listed below.

(a) The sample is intact, it is then returned to the boiler.

(b) The adhesion between the silicone rubber and the substrate fails, an adhesive failure is recorded.

(c) The sample fails in any other way (broken substrate, cohesive failure within the silicone rubber,...). The sample is excluded from further testing. This is recorded as a right-censored event. As the sample failed in a way that is not relevant to the study, it should not be excluded from the population. Rightcensorship allows us to consider the period it did survive, until it could no longer be tested, when computing the survival probability. The term right-censorship is best understood when imagining an axis of time, with the past to the left and the 
future to the right. If a sample is excluded before the failure mode under study is observed, only an aborted survival time (left of the exclusion day) is known. The actual failure day would have occurred to the right of the exclusion day, hence the event is right-censored.

\section{Statistical analysis and interpretation}

We use a two-parameter Weibull distribution to represent the sample population [30]. This distribution is common in reliability analysis and its merits have been discussed elsewhere [26].

The probability density function (pdf), Eq. (2), gives the probability of a sample failing on a given day $d(d>0)$. The cumulative density function $(\mathrm{cdf}), \mathrm{F}(\mathrm{T})$, gives the probability of a sample having failed by time $\mathrm{T}(\mathrm{T}>0)$. It can be used to calculate the probability of a sample surviving past $\mathrm{T}$ days. This last function is known as the reliability or survival function, commonly denoted by the letter R or $\mathrm{S}$ as in Eq. (3).

$$
\begin{aligned}
& f(d)=\left(\frac{\beta}{\eta^{\beta}}\right) * d^{(\beta-1)} * \mathrm{e}^{-\left(\frac{d}{\eta}\right)^{\beta}} \\
& S(T)=1-F(T)=e^{-\left(\frac{d}{\eta}\right)^{\beta}}
\end{aligned}
$$

$\beta$ is the shape parameter or Weibull modulus, and $\eta$ is the scale parameter and both are positive. The mean and standard deviation of the distribution, Eq. (4) and (5) respectively, are related to the gamma function.

$$
\begin{aligned}
& E(T)=\eta * \Gamma\left[1+\frac{1}{\beta}\right] \\
& \sigma(T)=\eta *\left\{\Gamma\left[1+\frac{2}{\beta}\right]-\Gamma\left[1+\frac{1}{\beta}\right]^{2}\right\}^{\frac{1}{2}}
\end{aligned}
$$

Figure 4 depicts the gamma function $\Gamma(\mathrm{x})$ and the Weibull distribution pdf. $\Gamma(\mathrm{x})$ is 1 for $\mathrm{x}=1$ and $\mathrm{x}=2$, has a minimum at $\mathrm{xmin}=1.4616$ where $\Gamma(\mathrm{xmin})=0.8856$ and is $>1$ for $0<x<1$ and $x>2$, as seen in Fig. 4a. Therefore, for $\beta>1$, the Gamma function is between its minimum (0.89) and 1 , and the mean of the distribution $\mathrm{E}(\mathrm{T})$ is such that $0.89 * \eta \leq \mathrm{E}(\mathrm{T}) \leq \eta$. The scale parameter $(\eta)$ gives an approximation of the mean time to failure (MTF), hence $\eta$ is sometimes called the characteristic life. The significance of the shape parameter $(\beta)$ is illustrated in Fig. $4 \mathrm{~b}$, showing Weibull pdfs, with the same scale parameter but different shape 
parameters, all $>1$. The higher the shape parameter, the higher the probability that the samples will fail at a time $\eta$ and the narrower the standard deviation for a given $\eta$. Practically, $\beta>1$ indicates wear out failures, for $\beta=1$ the failure rate is independent of the time and for $\beta<1$ it decreases with time.

The data were analyzed using Matlab R2010. Maximum likelihood estimates (MLE) of the two parameters were calculated using the function wblfit, taking the right-censored data into account. The function also returns upper and lower bounds for the parameters, with a confidence index $\alpha$ which, unless otherwise stated, was $95 \%$ for all data presented in this paper. The mean time to failure and standard deviation (std) for the population were then estimated (function wblstat or Eq. (4) and (5)), as well as the time by which there is an $n \%$ chance that a joint would have failed (and corresponding confidence interval CI). This last value is known as the $n^{\text {th }}$ percentile and denoted $y_{n}$.

The cdf of the distribution with the estimated parameters was then used to estimate the cumulative failure probabilities corresponding to the days at which failures were recorded. These probabilities and times to failure were plotted on probability axes, and the correlation coefficient and p-value calculated. Several data sets were plotted on the same graph for comparison (Fig. 5). The probability plots allow a visual inspection of the data sets to check if the assumption of a single failure mode is met. The data points should appear to be on a single line, without noticeable inflection (possibly indicative of a lognormal distribution) or corners, indicating a mixed failure modes situation.

The MTF and std of the distribution, plus scale parameter $(\eta)$ and shape parameter $(\beta)$, and the $\mathrm{R}$ and $\mathrm{p}$-value for all the sets tested are presented in Table 2.

\section{Results}

Figure 5 depicts the samples failure probability versus time for each adhesive/substrate couple at $\mathrm{pH} 1$.

The results are summarized in Table 2. The MTF ranges from 3.8 days $(\mathrm{CI}=3.2$ days -4.4 days $)$ to 30.1 days $(\mathrm{CI}=24.8$ days -36.5 days $)$ depending on the adhesive/substrate couple. The MED4-4220/alumina couple offers the best adhesion with an MTF of 30.1 days. The MED4-4220/FR4 couple also has a high MTF (25.1 days with $\mathrm{CI}=20.4$ days -30.9 days) but the Weibull shape parameter $(\beta)$ is higher for MED4-4220/alumina (3.2) than for MED4-4220/FR4 (2.9). The 
predicted MTF of the adhesive bonds at working temperature was estimated using an acceleration factor of 84 (Eq. (1)). The expected MTF at $37^{\circ} \mathrm{C}$ ranges from 10.6 months $(\mathrm{CI}=9$ months -12.3 months $)$ to 7 years $(5.8$ years -8.5 years $)$ depending on the adhesive/substrate couple (see Table 3 for values extrapolated at $\left.37^{\circ} \mathrm{C}\right)$.

Figure 6 compares the samples failure probability versus time for the MED44220/alumina couple at $\mathrm{pH} 1$ and $\mathrm{pH} \mathrm{7,} \mathrm{showing} \mathrm{the} \mathrm{impact} \mathrm{of} \mathrm{the} \mathrm{acidity.} \mathrm{The}$ MTF value is 13.7 times lower at $\mathrm{pH} 1$ (30.1 days) than at $\mathrm{pH} 7$ (412.9 days).

The standard $5 \mathrm{~kg}$ lap-shear test method was used to allow comparison with results from other studies. PEK Donaldson assessed the adhesive bond between 1part DC3140 and alumina at pH 4 and pH 7 [9]. We have calculated the MTFs and Weibull shape parameters from these published data and compared them to our results at $\mathrm{pH} 1$. Figure 6 shows the influence of the acidic environment. The MTF values are respectively 94.1 at $\mathrm{pH} 7,30.5$ at $\mathrm{pH} 4$ and 3.8 at $\mathrm{pH} 1$ while the shape parameters are 5.5, 7.2 and 4.2, respectively. The MTF is thus 24.8 times lower at $\mathrm{pH} 1$ than at $\mathrm{pH} 7$ for the DC3140/alumina couple. This ratio is much higher than that of the MED4-4220/alumina couple (13.7 times lower at pH 1 than at $\mathrm{pH} \mathrm{7;} \mathrm{Fig.} \mathrm{6).} \mathrm{Figure} 6$ also shows that the MTF is higher for the MED44220/alumina couple than for the DC3140/alumina couple, both at pH 7 (4.4 times higher) and at $\mathrm{pH} 1$ (7.9 times higher).

\section{Discussion}

\section{Material selection for a gastric stimulator implant}

We have studied the long-term stability of the adhesive bond between several couples of substrate and adhesive in simulated gastric liquid. Two silicone rubbers were tested on typical implant substrates at worst-case stomach pH. The MED44220 /alumina couple offered the best adhesion with a MTF of 30 days at $100^{\circ} \mathrm{C}$, resulting in a large predicted MTF at body temperature ( 7 years). The shape parameter was large and the cumulative failure probability for this couple reached $10 \%$ at 17 days, meaning that there is only a $10 \%$ chance that a sample will fail during the first 17 days. This corresponds to 3.9 years at $37^{\circ} \mathrm{C}$, sufficient for a first implantable prototype (see Table 3 for values extrapolated at $37^{\circ} \mathrm{C}$ ). 


\section{Comparison with gastric balloons}

Gastric balloons are interesting to compare to our gastric stimulators for at least two reasons: i) both devices aim to fight obesity (hence are competitors) and ii) both should resist the gastric environment (as discussed in the next section). Gastric balloons are typically used to fight obesity though with limited efficiency. Some of their major shortcomings include gastric ulceration, intolerance, difficulty in inflating or deflating the balloon, and spontaneous deflation of the balloon causing subsequent obstruction and complications during balloon withdrawal $[4,14,32,39]$. Since some of these complications have been associated with prolonged gastric implantation times [4] [28], the manufacturers typically recommend removal of gastric balloons six months after implantation [4, 14]. Therefore, the extrapolated MTF of 7 years and a $10^{\text {th }}$ percentile at 3.9 years, reported in this paper, are sufficient to propose gastrostimulator implants as advantageous alternatives to gastric balloons.

\section{The role of lipids and compression forces in the degradation of silicone rubbers}

We used a commercial simulated gastric fluid in our tests. Its composition is proprietary but the manufacturer confirmed that it is a mix of hydrochloric acid and sodium chloride without lipids or enzymes. While this choice follows industry standards [24], the gastric implant will be in contact with various other substances present in the food ingested by the patient. Lipids, for instance, are known to alter the cohesive strength of silicone rubbers [34, 37]. Gastric balloons are typically made of silicone elastomer $[13,31]$. One of their modes of failure is related to the gastric environment weakening the material [4, 16], which can lead to spontaneous deflation and resultant bowel obstruction [14]. This type of failure is related to the cohesive deterioration of the silicone elastomer while our study focuses on the adhesion between the silicone rubber and the substrate. The presence of lipids in the simulated gastric fluid would most certainly affect the bulk of the adhesive, resulting in cohesive failures, or right-censored events. However, cohesive strength is not a predictor of adhesive quality [7-9, 11]. Hence, while we cannot exclude that the lipids may also have an impact on the adhesive strength, we believe that the material selection method, and the results, presented here remain valid. 
Furthermore, gastric balloons are also subject to compression forces (natural peristalsis) when the stomach attempts to move them downstream. These compression forces combined with the presence of lipids could lead to a premature failure of the silicone rubber. In the case of our device, because of its smaller size and way of anchoring to the stomach wall (see following section), such compressions are not applied to it. This also argues in favour of our device.

\section{Considerations for the manufacture of a gastric stimulator implant}

Our group is currently developing a gastric stimulator prototype (Fig. 7). Based on the results of this study, alumina was chosen for the substrate and MED4-4220 for the adhesive. The device's physical design was conceived to permit anchoring by endoscopy. It is patented (Priority Date: 2009/05/08; Application number: PCT/EP2010/056378) and has been described elsewhere [25]. The electronic design and stimulation protocol are also described in [25].

For our prototype, as for any implant using silicone rubber encapsulation, the adhesive bond degradation could be quicker than predicted for various reasons. When encapsulating in silicone rubber an implant that includes soldered components, the solder should also be considered. The adhesive bond to solder is generally weaker than to the substrates tested [12] and the presence of flux can drive corrosion.

Cleanliness before encapsulation will also strongly influence the implant's lifetime [36]. Briefly, the cleaner the whole circuit and the substrate, the higher the osmotic gradient, should water vapour, which will rapidly permeate the encapsulation layer, find a condensation site. Liquid water formation would therefore be limited, and what would form would be highly resistive, hence limiting further loss of adhesion, and corrosion.

On our prototypes, we used a water soluble flux and the devices, after population, were thoroughly cleaned. After a rapid rinse in deionized water to flush the water soluble flux, they were immersed for several minutes in chloroform while a visual inspection, under a microscope, was conducted to identify any residual flux. After drying in air, the samples were cleaned in iso-propanol, and finally in the alkaline solution described before. None of the cleaning stages were precisely timed as we relied on visual inspection of critical points to assess the efficacy of the procedure. Eventually, the samples were rinsed three times in deionized water before a final 
rinse in flowing deionized water until the conductivity of the water flowing from the rinsing chamber reached an average value of $300 \mathrm{nS} / \mathrm{cm}$.

The presence of voids or air bubbles in the encapsulant may also negatively affect the implant's lifetime. Using the silicone rubber straight from the cartridge, without pre-processing, results in a surprisingly large number of small bubbles in the bulk of the silicone, as seen on the photograph of Fig. 8. Voids in the bulk of the silicone rubber, that are not in contact with the substrate or any part of the circuit, are not such a concern. If the substrate is thoroughly cleaned, the bubbles will become rapidly saturated with water vapour. Yet, as explained previously, even if some of it condenses, the osmotic gradient will drive it out of the bubble. Voids at the interface however are more troublesome as they decrease the overall surface area available for the silicone rubber to bond to the substrate. They also provide relatively large condensation sites for water vapour, where, if there is even minimal ionic contamination, the liquid water may support corrosion.

In this respect, our tests samples were sub-optimal. This may have accelerated the failure rate, hence our results may underestimate the survival rate that could be achieved with bubble-free adhesive. We have adapted our method to prevent the formation of these voids and air bubbles in our prototypes.

The MED4-4220 is degazed in a vacuum centrifuge for not more than 5 minutes at 25 mbar before being poured in the reservoir of the mould. After centrifugal casting during 2 to 5 minutes, the filled mould is cured in an oven during 2 hours minimum, sufficient to crosslink the silicone rubber.

A final consideration when designing an implant is that the failure rate of electronic devices protected by silicone rubber encapsulation is proportional to the field-strength between exposed conductors. We have taken care, during the electronic design, to minimise these fields.

\section{Other applications in implanted devices}

Besides the direct benefit for gastric implants, our research also has implications for various other applications. Due to the current manufacturing bottleneck in implanted device protection (see introduction), silicone rubber encapsulation has recently received an increased interest $[35,36]$. A manufacturing breakthrough is needed to enable technical applications requiring small dimensions and high reliability $[18,42]$. Most of them fall into the area of electrical stimulation, one of 
the fastest-growing areas of medicine, improving the lives of hundreds of thousands of patients with various disorders [23]. Visual prostheses are perhaps the most striking example with clear space constraints for which the current protection methods are not suitable [29].

Silicone rubber encapsulation offers a simple yet reliable way to protect implants. Using this method, prototypes using discrete components may be designed and developed rapidly. Besides prototypes, implants encapsulated with silicone rubber have been in use, in patients, for decades, demonstrating the suitability of the method for commercial production [2].

\section{Conclusion}

We have presented a method to select a silicone rubber for the encapsulation of an electronics circuit to provide long-term protection for implantation. We have presented the event recording and failure analysis in depth. In this paper we have used the method to identify a suitable silicone rubber/substrate couple for the production of an implantable gastrostimulator.

Compared to previous publications, this study is of major importance for two reasons. First, the samples were immersed in a $\mathrm{pH}$ equivalent to the stomach environment, which is lower than the acidity levels previously tested. Second, a new rubber was introduced and tested.

This study shows that this promising technique is also suitable for devices operating in highly acidic environments. In particular, the combination of alumina with MED4-4220 may provide up to 3.9 years at body temperature with less than $10 \%$ failed devices, hence is suitable for most gastrostimulator applications. This is of major importance in the fight against obesity as these implants could improve the well-being of obese patients during and after their medical intervention. Further work will include implanting stimulators in animal models to improve the endoscopic attachment method and assess the weight loss during stimulation at the pylorus. It will also include an analysis of the impact of various substances present in the food to complement the results presented here.

\section{Acknowledgment}

The authors would like to acknowledge Mr. Bruno Tartini and Mr. Geoffrey Vanbienne for their contribution to the lap-shear tests. 


\section{References}

1. Borton DA, Yin M, Aceros J, Nurmikko A (2013) An implantable wireless neural interface for recording cortical circuit dynamics in moving primates. J Neural Eng 10(2):026010026026

2. Brindley G (1994) The first 500 patients with sacral anterior root stimulator implants: general description. Paraplegia 32(312):795-805

3. Cilluffo T, Armstrong D, Castiglione F, Emde C, Galeazzi R, Gonvers JJ, Blum AL (1990) Reproducibility of ambulatory gastric ph recordings in the corpus and antrum. Scand $\mathrm{J}$ Gastroenterol 25(10):1076-1083

4. De Castro ML, Morales MJ, Martínez-Olmos MA, Pineda JR, Cid L, Estévez P, Del-Campo V, Rodriguez-Prada, JI (2013) Safety and effectiveness of gastric balloons associated with hypocaloric diet for the treatment of obesity. Rev Esp Enferm Dig 105(9):529-536

5. Deb S, Tang SJ, Abell TL, Rao S, Huang WD, Lahr C, Chiao JC (2012) An endoscopic wireless gastrostimulator (with video). Gastrointest Endosc 75(2):411-415

6. Donaldson NN, Donaldson PEK (2000) Speeding-up the cure of one-part silicone rubber, when encapsulating neurological prostheses : the permeable mould. Med Eng Phys 22:301306

7. Donaldson PEK (1982) The underwater life of joints between adherend and adhesive materials useful in neurological prosthesis-making. In: Proc. International Conference on Biomedical Polymers, Biological Engineering Society/Plastics \& Rubber Institute, Durham, UK.

8. Donaldson PEK (1994) Hydrothermal stability of joints, using a silicone robber adhesive, for a range of adherends of interest to makers of surgically-implanted microelectronic devices. Int J Adhes Adhes 14(2):103-107

9. Donaldson PEK (1995) Aspects of silicone rubber as encapsulant for neurological prostheses. Part 3: adhesion to mixed oxides. Med Biol Eng Comput 33(5):725-727

10. Donaldson PEK (1997) Aspects of silicone rubber as encapsulant for neurological prostheses. Part 4: two-part rubbers. Med Biol Eng Comput 35:283-286

11. Donaldson PEK, Aylett BJ (1995) Aspects of silicone rubber as encapsulant for neurological prostheses. Part 2: adhesion to binary oxides. Med Biol Eng Comput 33(3):289-292

12. Donaldson PEK, Sayer E (1981) A technology for implantable hermetic packages. Part 2: an implementation. Med Biol Eng Comput 19(4):403-405

13. Espinet-Coll E, Nebreda-Durán J, Gómez-Valero JA, Muñoz-Navas M, Pujol-Gebelli J, VilaLolo C, Martinez-Gomez A, Juan-Creix-Comamala A (2012) Current endoscopic techniques in the treatment of obesity. Rev. Esp. Enferm. Dig. 104(2):72-87

14. Evans JT, DeLegge MH (2011) Intragastric balloon therapy in the management of obesity: why the bad wrap? J Parenter Enteral Nutr 35(1):25-31

15. Finucane MM, Stevens G, Cowan MJ, Danaei G, Lin JK, Paciorek CJ, Singh GM, Gutierrez HR, Lu Y, Bahalim AN, Farzadfar F, Riley LM, Ezzati M (2011) National, regional, and global trends in body-mass index since 1980: systematic analysis of health examination 
surveys and epidemiological studies with 960 country-years and 9.1 million participants. Lancet 377(9765):557-567

16. Genco A, Dellepiane D, Baglio G, Cappelletti F, Frangella F, Maselli R, dante MC, Camoirano R, Lorenzo M, Basso N (2013) Adjustable intragastric balloon vs non-adjustable intragastric balloon: case-control study on complications, tolerance, and efficacy. Obes. Surg. 23(7):953-958

17. Green RA, Guenther T, Jeschke C, Jaillon A, Yu JF, Dueck WF, Lim WW, Henderson WC, Vanhoestenberghe A, Lovell NH, Suaning GJ (2013) Integrated electrode and high density feedthrough system for chip-scaleoogle implantable devices. Biomaterials 34(26):6109-6118

18. Harkema S, Gerasimenko Y, Hodes J, Burdick J, Angeli C, Chen Y, Ferraira C, Willhite A, Rejc E, Grossman RG, Edgerton VR (2011) Effect of epidural stimulation of the lumbosacral spinal cord on voluntary movement, standing, and assisted stepping after motor complete paraplegia: a case study. Lancet 377(9781):1938-1947

19. Hasler WL (2009) Methods of gastric electrical stimulation and pacing: a review of their benefits and mechanisms of action in gastroparesis and obesity. Neurogastroent Motil 21(3):229-243

20. Herron DM, Birkett DH, Thompson CC, Bessler M, Swanström LL (2008) Gastric bypass pouch and stoma reduction using a transoral endoscopic anchor placement system: a feasibility study. Surg Endosc 22(4):1093-1099

21. Ibrahim M, Blero D, Deviere J (2010) Endoscopic options for the treatment of obesity. Gastroenterol 138(7):2228-2232

22. Jiang G, Zhou DD (2010) Technology Advances and Challenges in Hermetic Packaging for Implantable Medical Devices. In: Zhou DD, Greenbaum E (eds) Implantable Neural Prostheses 2. Biological and Medical Physics, Biomedical Engineering, Springer New York, pp 27-61

23. Krames ES, Hunter Peckham P, Rezai AR (2009) Neuromodulation. Academic Press, Elsevier Ltd.

24. Lindberg M. (2011) Case study : aging study of silicone materials in simulated gastric fluid. https://www.silicone-polymers.co.uk/pdf2011/Case\%20Study-

Aging\%20Study\%20of\%20Silicone\%20Materials\%20in\%20Simulated\%20Gastric\%20Fluid. pdf

Accessed 1 Sept 2014

25. Lonys L, Hiernaux M, Cauche N, Devière J, Vanhoest A, Mathys P, Nonclercq A (2011) Challenges for the design of an endoscopically implanted electrostimulator. In: Communication A, Machado P, 16th Annual Conference of the International Functional Electrical Stimulation Society, Atha Communication and Publishing Machado, Sao Paulo, Brazil

26. Nelson WB (1982) Applied Life Data Analysis. John Wiley \& Sons, Inc., Hoboken, New Jersey

27. Nusil (2012) Avoiding inhibition when working with platinum catalyzed silicones. p. 9905 
28. Roman S, Napoléon B, Mion F, Bory R-M, Guyot P, D’Horazio H, Benchetrit S (2004) Intragastric balloon for "non-morbid" obesity: a retrospective evaluation of tolerance and efficacy. Obes Surg 14(4):539-544

29. Rothermel A, Liu L, Aryan NP, Fischer M, Wuenschmann J, Kibbel S, Harscher A (2009) A cmos chip with active pixel array and specific test features for subretinal implantation. IEEE J Solid-State Circuits 44(1):290-300

30. Scholz F (2008) Inference for the weibull distribution. http://www.stat.washington.edu/fritz/DATAFILES498B2008/WeibullBounds.pdf Accessed 7 Aug 2013

31. Silimed (2010). Instruction for use: Gastric balloon. http://medikell.hu/uploads/images/file/INSTRUCTIONS\%20FOR\%20USE.pdf Accessed 1 Sept 2014

32. Subei IM, Abdelazim A, Bayoumi A, Wahab MA, Deriny SE (1996) The effect of different types of intragastric balloons with and without a behavior modification program in morbid obesity. Saudi J Gastroenterol 2(2):63-68

33. Traeger RK, Sandia L (1977) Nonhermeticity of polymeric lid sealants. IEEE Trans Parts, Hybrids, Packag 13(2):147-152

34. Trudel J, Gauderer MWL, Drews MJ, LaBerge M (1998) Lipid uptake by silicone enteral access feeding devices. J Pediatr Surg 33(6):880-884

35. Vanhoestenberghe A, Donaldson N (2013) Corrosion of silicon integrated circuits and lifetime predictions in implantable electronic devices. J Neural Eng 10(3):1002-1015

36. Vanhoestenberghe A, Donaldson N (2011) The limits of hermeticity test methods for micropackages. Artif Organs 35(3):242-244

37. Williams DF (1982) Biodegradation of surgical polymers. J Mater Sci 17:1233-1246

38. Withrow D, Alter DA (2011) The economic burden of obesity worldwide: a systematic review of the direct costs of obesity. Obes Rev 12(2):131-141

39. Yap Kannan R, Nutt MR (2013) Are intra-gastric adjustable balloon system safe? A case series. Int J Surg Case Rep 4(10):936-938

40. Yin M, Borton DA, Aceros J (2013) A 100-channel hermetically sealed implantable device for chronic wireless neurosensing applications. 7(2):115-128

41. Yin M, Li H, Bull C, Borton DA, Aceros J, Larson L, Nurmikko AV (2013) An externally head-mounted wireless neural recording device for laboratory animal research and possible human clinical use. Conf Proc IEEE Eng Med Biol Soc:3109-3114

42. Zhou D, Greenbaum E (2009) Implantable Neural Prostheses 1: Devices and applications. Biological and Medical Physics, Biomedical Engineering, Springer New York. 


\section{Figure captions}

Fig. 1 Sketches comparing examples of the encapsulation (a) and hermetic packaging (b) as methods of protecting an IC for human implantation

Fig. 2 Two adherent pieces bonded with an adhesive layer of silicone rubber. The thickness is 500 $\mu \mathrm{m}$ thickness and the area is $25.4 \mathrm{~mm}$ per $3 \mathrm{~mm}$

Fig. 3 Joining jig and its dimensions allowing the correct thickness of the adhesive layer

Fig. 4 (a) Gamma function (b) Weibull distribution pdf with the same scale parameter and different shape parameters : squares are for beta $=10$, mean $=9.5135$, std $=1.1446$, crosses are for beta $=4$, mean $=9.064, \mathrm{std}=2.5429$, triangles are for beta $=2$, mean $=8.8623, \mathrm{std}=4.6325$, circles are for beta $=1.1$, mean $=9.6491, \mathrm{std}=8.7828$

Fig. 5 Weibull plots for the different couples tested at pH 1: asterisks are for DC3140/alumina, open circles are for DC3140/FR4, crosses are for MED4-4220/glass, squares are for DC3140/glass, triangles are for MED4-4220/FR4, closed circles are for MED4-4220/alumina

Fig. 6 Influence of the acidic environment: asterisks are for DC3140/alumina at pH 1, closed circles are for MED4-4220/alumina at $\mathrm{pH} 1$, triangles are for DC3140/alumina at $\mathrm{pH} 4$, crosses are for DC3140/alumina at $\mathrm{pH} 7$, squares are for MED4-4220/alumina at $\mathrm{pH} 7$

Fig. 7 Illustration of our first prototype of an encapsulated gastrostimulator

Fig. 8 Illustration (optical photograph) of water bubbles between the substrate and the silicone after an adhesive failure (top view) 


\section{Tables}

Table 1. Main properties of DC3140 and MED4-4220

\begin{tabular}{|l|l|l|}
\hline & DC3140 & MED4-4220 \\
\hline Manufacturer & Dow Corning & Nusil \\
\hline Cure system & Alkoxy & Platinum \\
\hline Work time & 25 min & 25 min \\
\hline Mix ratio & 1 -part & 2 -part 1:1 \\
\hline Cure time & 72 h @ RT & $\begin{array}{l}15 \text { min @ } 150^{\circ} \mathrm{C} \\
24 \mathrm{~h} @ \text { RT }\end{array}$ \\
\hline Durometer Hardness Shore A & 32 & 17 \\
\hline Tensile modulus (MPa) & 0.7 & 4.5 \\
\hline Tensile strength (Mpa) & 3.1 & 5.3 \\
\hline Tear strength (kN/m) & 3.6 & 20500 \\
\hline Uncured viscosity (mPa.s) & 35950 & \\
\hline
\end{tabular}


Table 2. Results (samples bathed at $100^{\circ} \mathrm{C}$ )

\begin{tabular}{|c|c|c|c|c|c|c|c|}
\hline & $\begin{array}{l}\text { Scale } \\
\text { parameter } \\
(\eta) \text { [days] }\end{array}$ & $\begin{array}{l}\text { Shape } \\
\text { parameter } \\
(\beta)[]\end{array}$ & $\begin{array}{l}\text { MTF } \\
\text { [days] }\end{array}$ & $\begin{array}{l}\text { Std of } \\
\text { cdf } \\
\text { [days] }\end{array}$ & $\begin{array}{l}\operatorname{Pr}<0.1 \\
{[\text { days }]}\end{array}$ & $\begin{array}{l}\mathrm{R} \\
{[]}\end{array}$ & $\begin{array}{l}\text { P value } \\
{[]}\end{array}$ \\
\hline $\begin{array}{l}\mathrm{DC} 3140 / \mathrm{Al}_{2} \mathrm{O}_{3} \\
(\mathrm{pH} \mathrm{1})\end{array}$ & 4.1 & 4.2 & 3.8 & 1 & 2.4 & 0.83 & $\begin{array}{l}48.44 \\
\text { e-05 }\end{array}$ \\
\hline $\begin{array}{l}\text { DC3140/FR4 } \\
\text { (pH 1) }\end{array}$ & 9.7 & 3.2 & 8.7 & 2.9 & 4.8 & 0.86 & $\begin{array}{l}7.09 \\
\text { e-05 }\end{array}$ \\
\hline $\begin{array}{l}\text { DC3140/Glass } \\
(\mathrm{pH} \mathrm{1)}\end{array}$ & 16 & 2.6 & 14.2 & 5.9 & 6.7 & 0.97 & $\begin{array}{l}3.53 \\
e-07\end{array}$ \\
\hline $\begin{array}{l}\text { MED4-4220/ } / \mathrm{Al}_{2} \mathrm{O}_{3} \\
(\mathrm{pH} \mathrm{1)}\end{array}$ & 33.6 & 3.2 & 30.1 & 10.3 & 16.6 & 0.93 & $\begin{array}{l}5.44 \\
e-06\end{array}$ \\
\hline $\begin{array}{l}\text { MED4-4220/FR4 } \\
\text { (pH 1) }\end{array}$ & 28.1 & 2.9 & 25.1 & 9.3 & 13 & 0.98 & $\begin{array}{l}2.31 \\
e-09\end{array}$ \\
\hline $\begin{array}{l}\text { MED4-4220/Glass } \\
\text { (pH 1) }\end{array}$ & 9.4 & 10.4 & 9 & 1 & 7.6 & 0.94 & $\begin{array}{l}4.37 \\
e-07\end{array}$ \\
\hline $\begin{array}{l}\mathrm{DC} 3140 / \mathrm{Al}_{2} \mathrm{O}_{3} \\
(\mathrm{pH} \mathrm{4})\end{array}$ & 32.5 & 7.2 & 30.5 & 5 & 23.8 & 0.91 & $\begin{array}{l}57.21 \\
\text { e- } 05\end{array}$ \\
\hline $\begin{array}{l}\mathrm{DC} 3140 / \mathrm{Al}_{2} \mathrm{O}_{3} \\
(\mathrm{pH} 7)\end{array}$ & 101.9 & 5.5 & 94.1 & 19.8 & 67.6 & 0.94 & $\begin{array}{l}20.05 \\
e-05\end{array}$ \\
\hline $\begin{array}{l}\mathrm{MED} 4-4220 / \mathrm{Al}_{2} \mathrm{O}_{3} \\
(\mathrm{pH} 7)\end{array}$ & 451.4 & 1.4 & 412.9 & 305.3 & 87.1 & 0.95 & $\begin{array}{l}4.57 \\
e-07\end{array}$ \\
\hline
\end{tabular}


Table 3. Results at $100^{\circ} \mathrm{C}$ and extrapolated values at $37^{\circ} \mathrm{C}$

\begin{tabular}{|c|c|c|c|c|}
\hline & \multicolumn{2}{|c|}{ Results at $100^{\circ} \mathrm{C}$} & \multicolumn{2}{|c|}{ Extrapolated values at $37^{\circ} \mathrm{C}$} \\
\hline & $\begin{array}{l}\text { MTF } \\
\text { [days] }\end{array}$ & $\begin{array}{l}\operatorname{Pr}<0.1 \\
{[\text { days] }}\end{array}$ & $\begin{array}{l}\text { MTF } \\
\text { [years] }\end{array}$ & $\begin{array}{l}\operatorname{Pr}<0.1 \\
{[\text { years] }}\end{array}$ \\
\hline $\begin{array}{l}\mathrm{DC} 3140 / \mathrm{Al}_{2} \mathrm{O}_{3} \\
(\mathrm{pH} 1)\end{array}$ & 3.8 & 2.4 & 0.9 & 0.6 \\
\hline $\begin{array}{l}\text { DC3140/Glass } \\
\text { (pH 1) }\end{array}$ & 14.2 & 6.7 & 3.3 & 1.6 \\
\hline $\begin{array}{l}\text { DC3140/FR4 } \\
\text { (pH 1) }\end{array}$ & 8.7 & 4.8 & 2 & 1.1 \\
\hline $\begin{array}{l}\mathrm{MED} 4-4220 / \mathrm{Al}_{2} \mathrm{O}_{3} \\
(\mathrm{pH} 1)\end{array}$ & 30.1 & 16.6 & 7 & 3.9 \\
\hline $\begin{array}{l}\text { MED4-4220/Glass } \\
(\mathrm{pH} \mathrm{1)}\end{array}$ & 9 & 7.6 & 2.1 & 1.8 \\
\hline $\begin{array}{l}\text { MED4-4220/FR4 } \\
(\mathrm{pH} \mathrm{1)}\end{array}$ & 25.1 & 13 & 5.9 & 3 \\
\hline $\begin{array}{l}\mathrm{DC} 3140 / \mathrm{Al}_{2} \mathrm{O}_{3} \\
(\mathrm{pH} 4)\end{array}$ & 30.5 & 23.8 & 7.1 & 5.6 \\
\hline $\begin{array}{l}\mathrm{DC} 3140 / \mathrm{Al}_{2} \mathrm{O}_{3} \\
(\mathrm{pH} 7)\end{array}$ & 94.1 & 67.6 & 22 & 15.8 \\
\hline $\begin{array}{l}\mathrm{MED} 4-4220 / \mathrm{Al}_{2} \mathrm{O}_{3} \\
(\mathrm{pH} 7)\end{array}$ & 412.9 & 87.1 & 96.3 & 20.3 \\
\hline
\end{tabular}









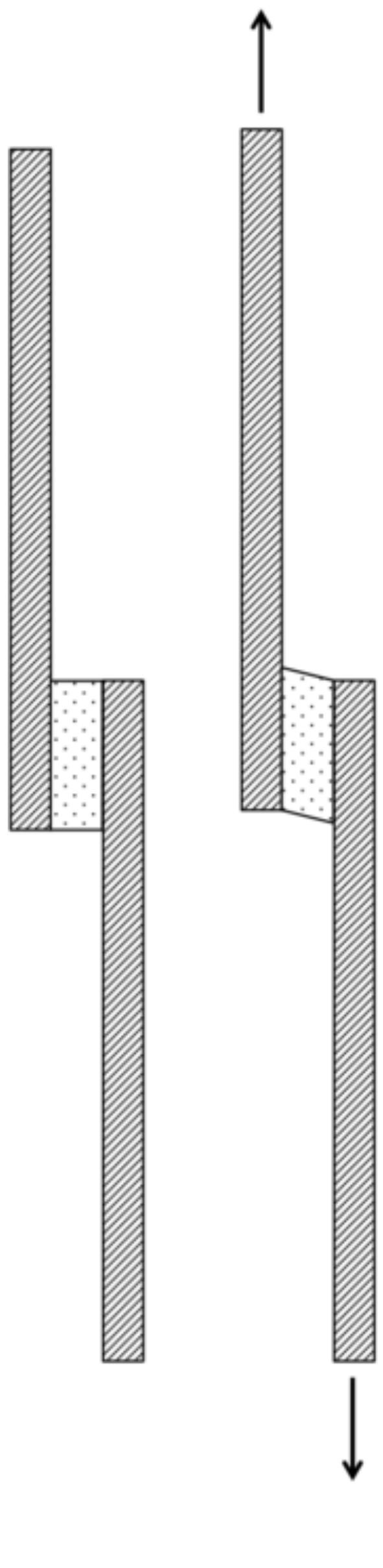




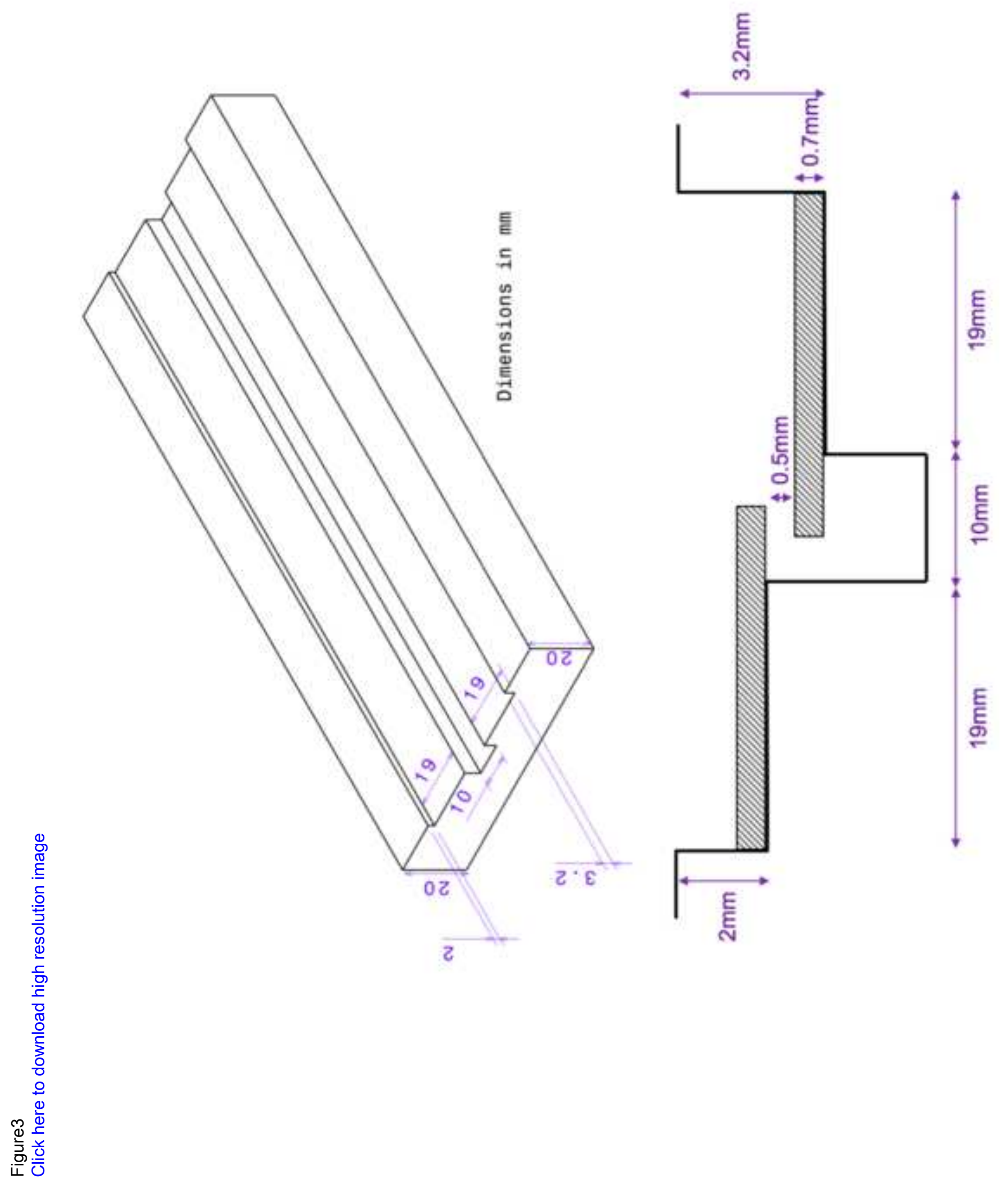




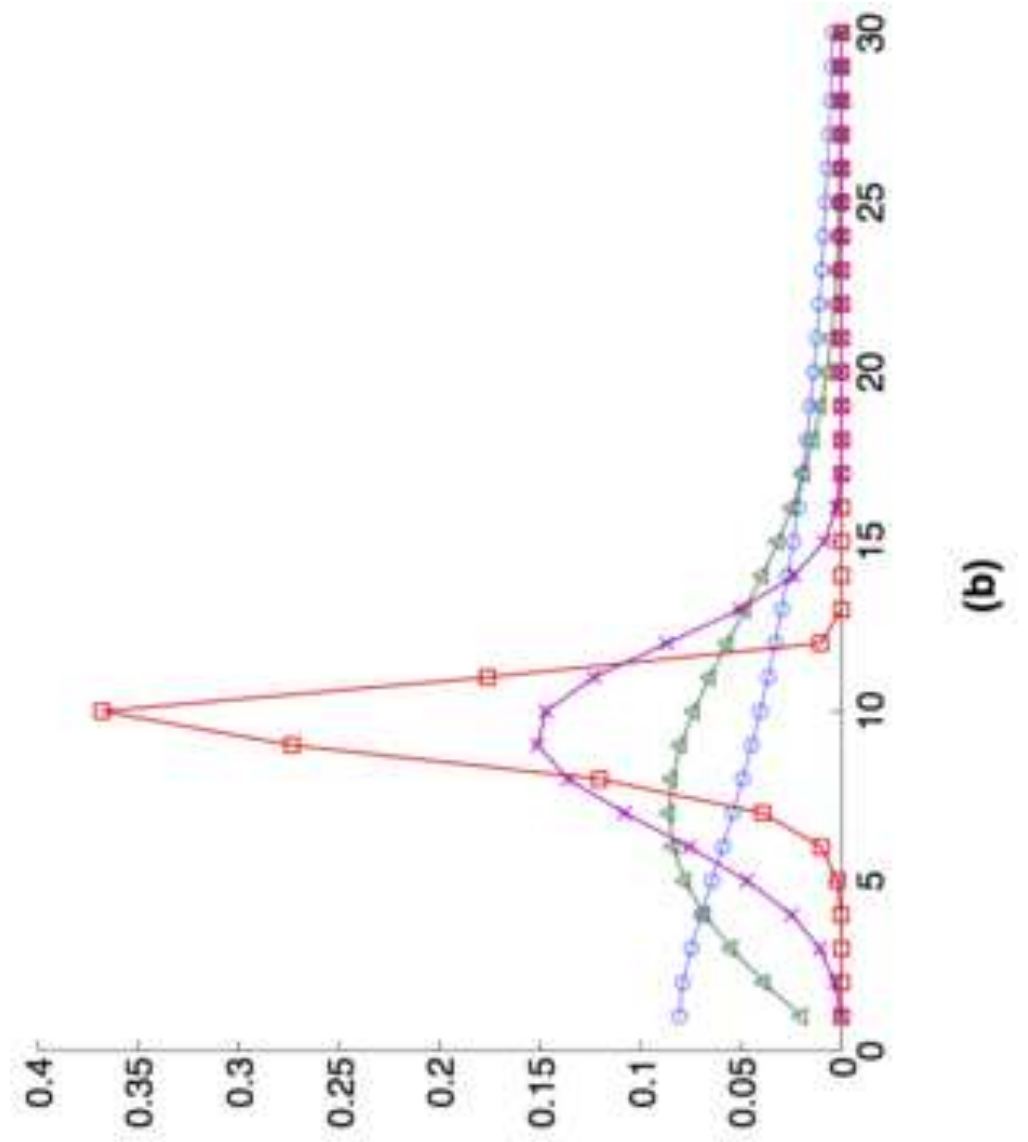

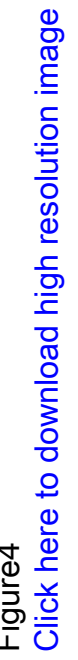

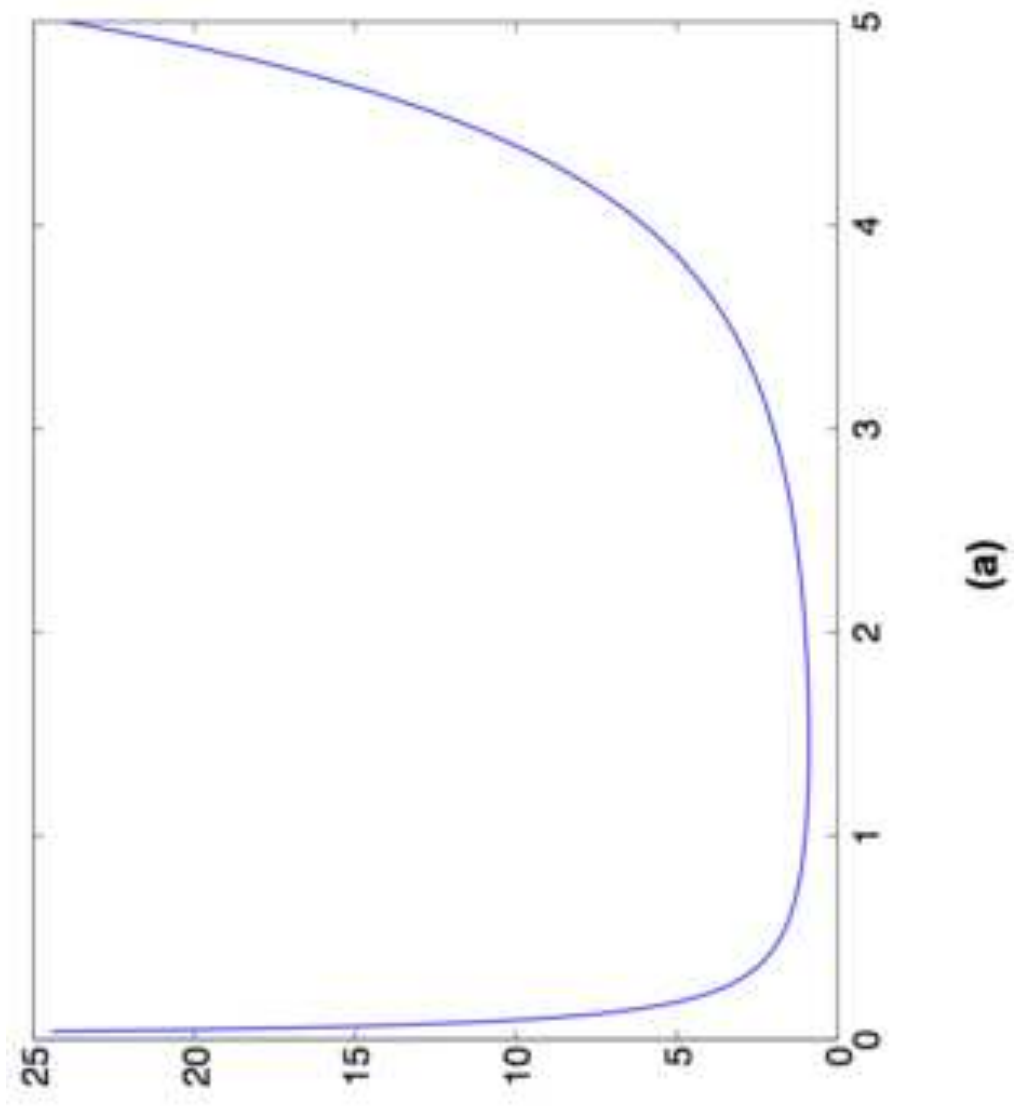


Click here to download Figure: figure5.eps

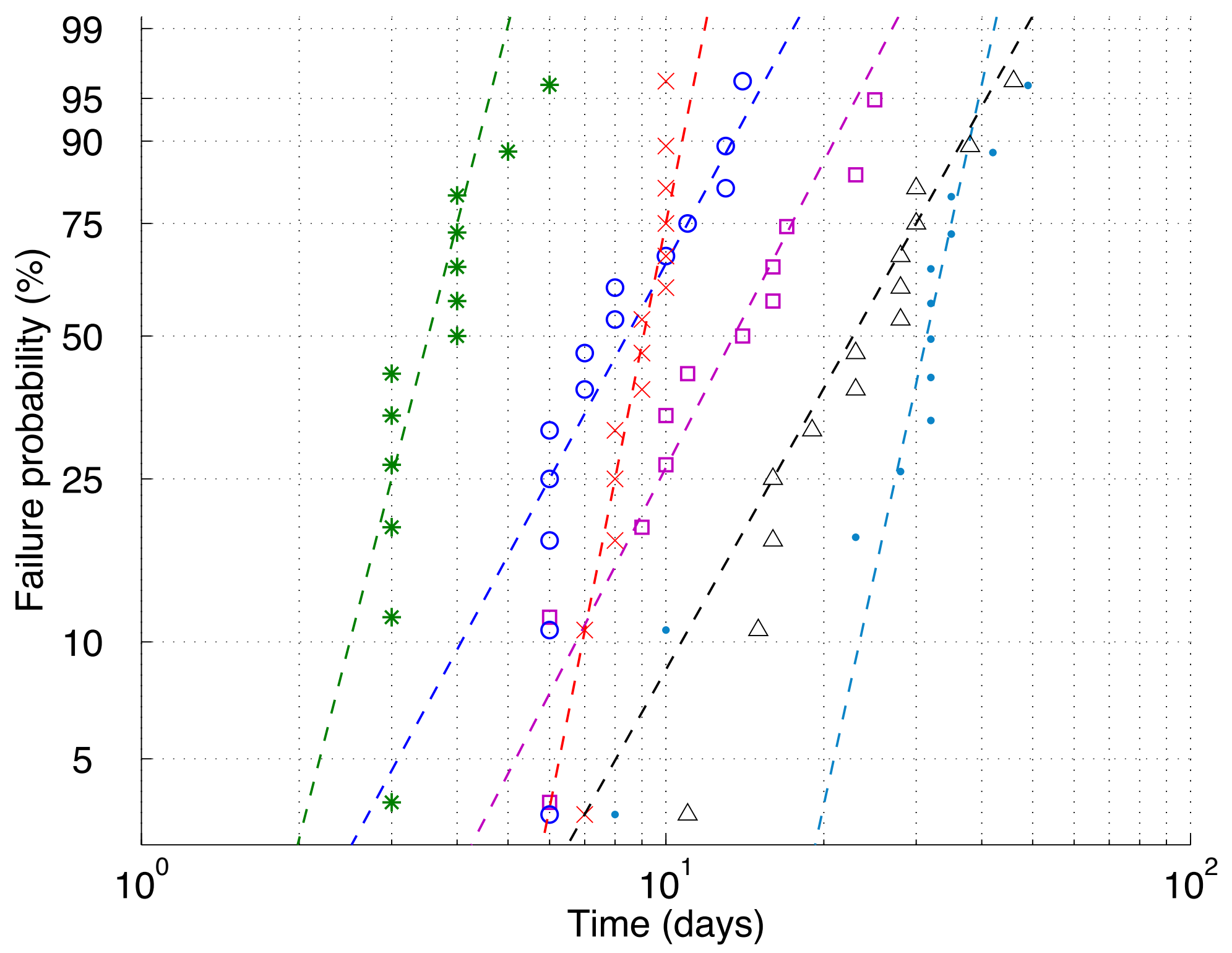


Click here to download Figure: figure6.eps

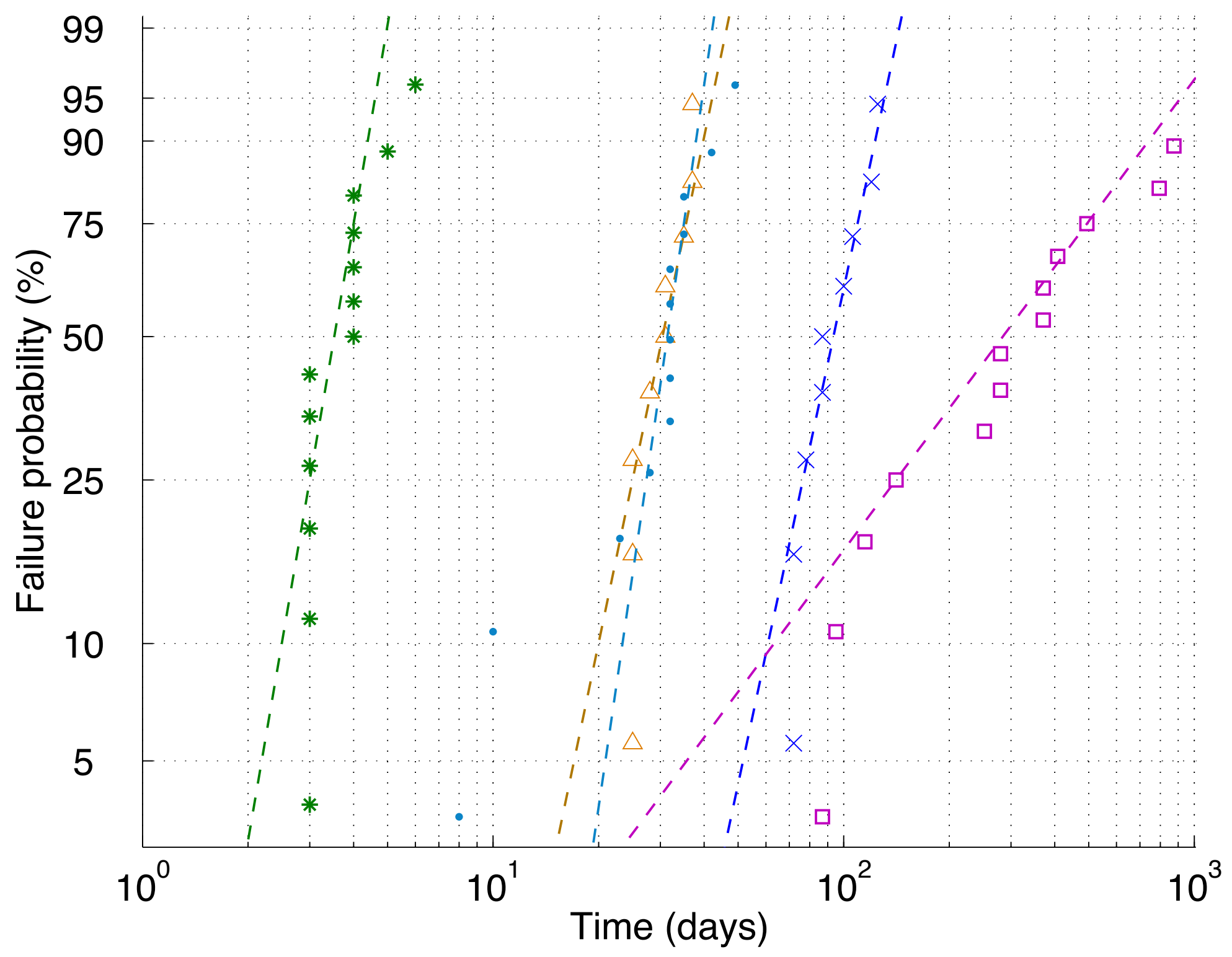



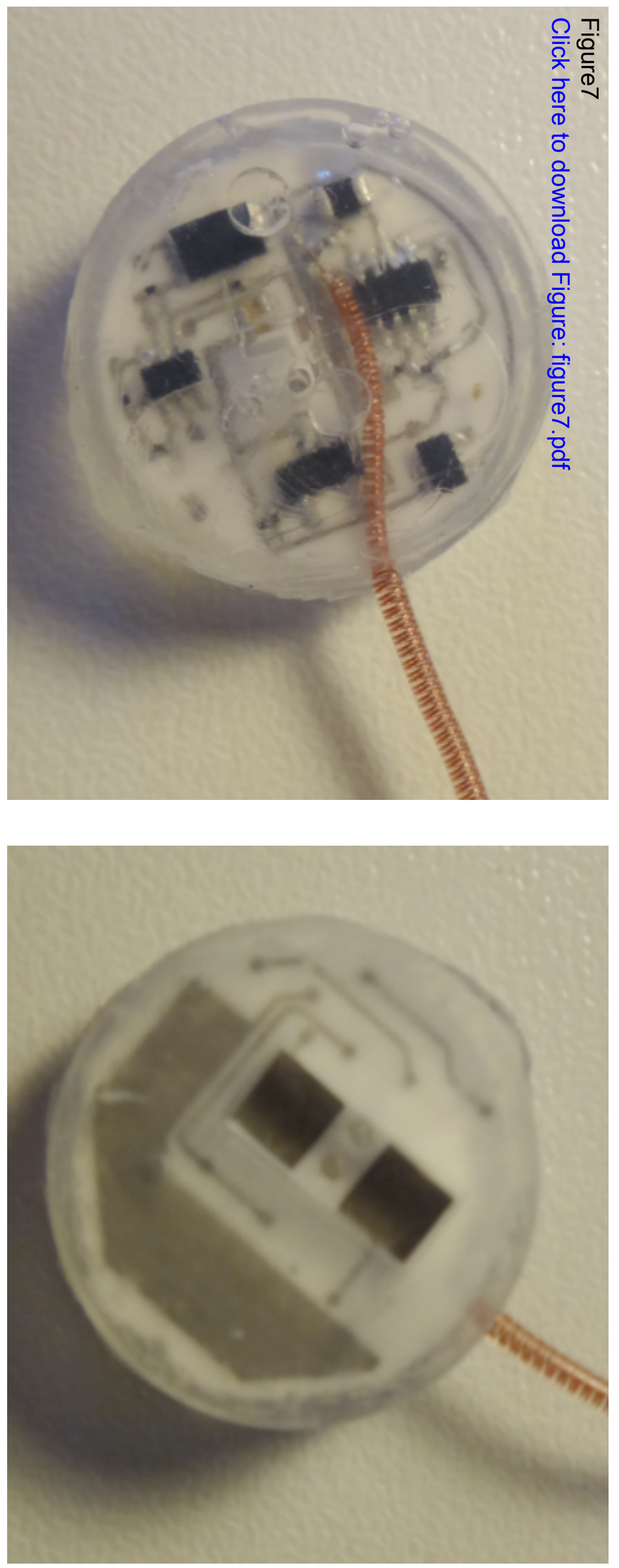

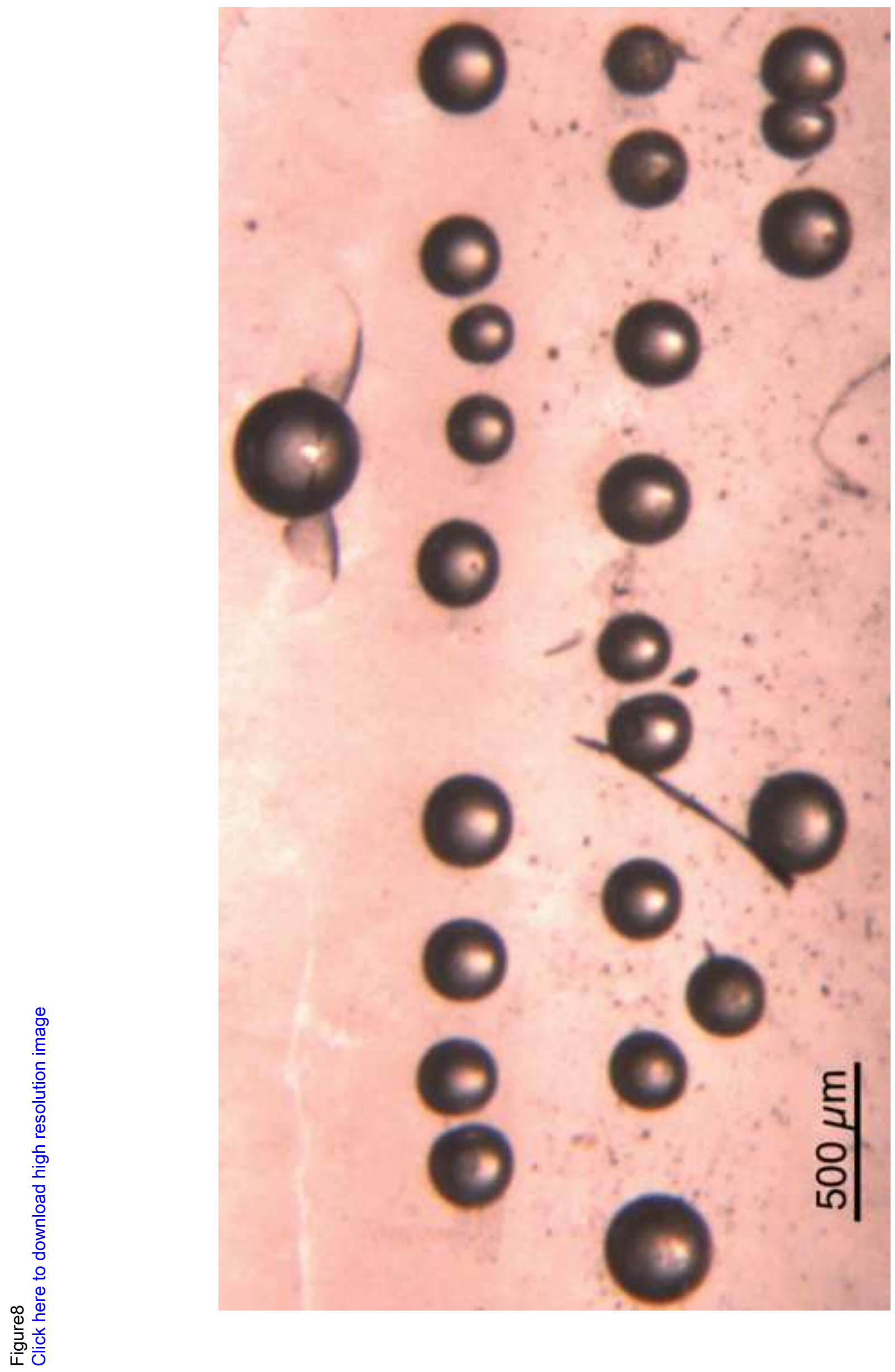

产는 